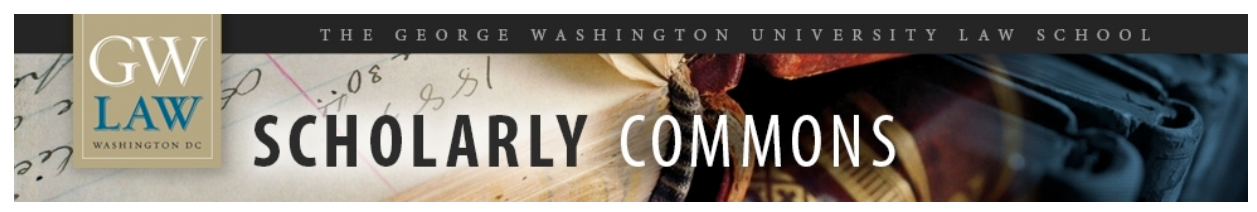

\title{
Cultural Cognition and Synthetic Biology Risk Perceptions: A Preliminary Analysis
}

Donald Braman

George Washington University Law School, dbraman@law.gwu.edu

Gregory N. Mandel

Dan M. Kahan

Follow this and additional works at: https://scholarship.law.gwu.edu/faculty_publications

Part of the Law Commons

\section{Recommended Citation}

Braman, Donald; Mandel, Gregory N.; and Kahan, Dan M., "Cultural Cognition and Synthetic Biology Risk Perceptions: A Preliminary Analysis" (2008). GW Law Faculty Publications \& Other Works. 282. https://scholarship.law.gwu.edu/faculty_publications/282

This Article is brought to you for free and open access by the Faculty Scholarship at Scholarly Commons. It has been accepted for inclusion in GW Law Faculty Publications \& Other Works by an authorized administrator of Scholarly Commons. For more information, please contact spagel@law.gwu.edu. 


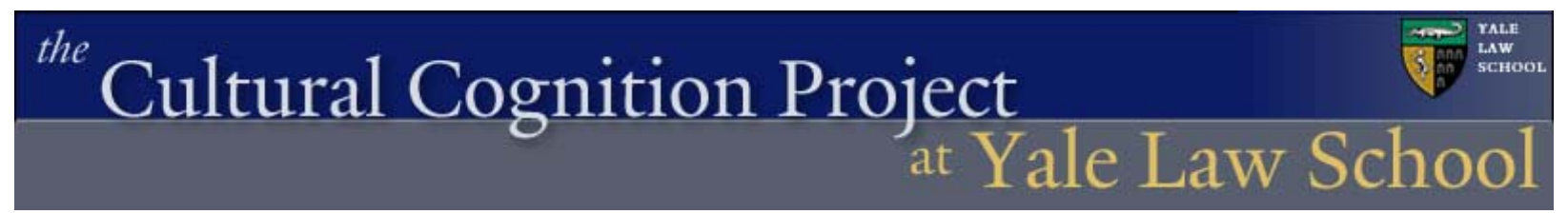

\title{
The Cultural Cognition of Synthetic Biology Risks: \\ A Preliminary Analysis
}

\author{
A Study Conducted by the \\ Cultural Cognition Project at Yale Law School
}

Gregory Mandel
Temple University
Beasley School of Law

\author{
Donald Braman \\ George Washington Law \\ School
}

September 5, 2008

Research Supported by

National Science Foundation, Grant SES 0621840

The Oscar Ruebhausen Fund at Yale Law School 


\title{
The Cultural Cognition of Synthetic Biology Risks: A Preliminary Analysis
}

\author{
Cultural Cognition Project at Yale Law School
}

\author{
Gregory Mandel \\ Temple University \\ Beasley School of Law
}

\author{
Donald Braman \\ George Washington \\ Law School
}

\author{
Dan Kahan \\ Yale Law School
}

\section{Introduction and Summary of Conclusions}

Synthetic biology is an emerging technology that permits scientists to design living organism unlike any found in nature. Such organisms, it is hoped, might be put to myriad beneficial uses, including the treatment of disease, the elimination of environmental pollutants, and the production of new sources of energy. However, engineered life forms also might pose risks to the environment and to human health; exactly what those hazards are and how they might be contained cannot fully be determined in advance of the very research necessary to perfect development of this novel science. Will the public resist the advent of a science the risks and benefits of which remain attended by this degree of uncertainty? And how might that reaction be influenced by the public's moral and emotional response to the prospect of substituting human agency for the subtle processes of nature in determining what shapes life takes on our planet?

The Cultural Cognition Project (CCP) conducted a survey study of 1,500 Americans aimed at determining who thinks what about the benefits and risks of synthetic biology. This report offers a preliminary analysis of the study results. Key findings include:

1. How much individuals know about synthetic biology has little relationship with their opinions about its risks and benefits. Synthetic biology remains relatively unfamiliar to most Americans. Over $80 \%$ of the survey respondents indicated that they knew either "little" or "nothing" about synthetic biology. However, the vast majority of subjects had an opinion on whether its benefits would outweigh its risks, and there was not a significant difference between those who reported little or no knowledge and the those who reported being more familiar with synthetic biology.

2. There were significant group divisions over the benefits and risks of synthetic biology. Although a majority of respondents expected synthetic biology benefits to outweigh risks, there were strong differences of opinion across societal groups. Thus, men differed significantly from women, whites from minorities, republicans from democrats, and liberals from conservatives. 
3. Disagreement about synthetic biology risks and benefits displays a distinctive cultural profile. Like disputes over other environmental risks, disputes over synthetic biology risks are linked up to cultural values. But the nature of the cultural conflict over synthetic biology is distinctive. In general, individuals who hold relatively egalitarian values tend to be more risk sensitive and those who hold relatively hierarchical values more risk skeptical concerning technological and environmental risks. On synthetic biology, this relationship is reversed. Religiosity and conservativism, which likewise tend to be correlated with environmental risk skepticism, also predict more concern over synthetic biology risks. These results suggest that the social meaning of the synthetic biology risks differs from that of other technological and environmental risks: recognition of global warming and nuclear power risks, for example, tends to be associated with challenges to authority, a connotation that repels persons who are culturally hierarchical, politically conservative, and religious; recognition of synthetic biology risks, in contrast, coheres with resentment of a form of cultural secularism, symbolized by science, that is itself subversive of traditional forms of authority. Cultural conflict over synthetic biology is thus likely to differ, not in its intensity but in its composition, from conflict over other environmental and technological risks.

4. Additional study is warranted. The findings of this study underscore the importance of additional research into how cultural cognition relates to synthetic biology. Experimental investigation is warranted both to identify the processes through which cultural outlooks are most likely to influence synthetic biology risk perceptions and to devise strategies of communication that assure the best available science is accessible to persons of diverse cultural outlooks.

\section{Overview of Study}

The study involved an on-line survey of a diverse sample of 1,500 American adults representative of the U.S. population. ${ }^{1}$ Subjects' cultural values were measured with scales used in the study of the cultural cognition of risk (Kahan, Braman, Gastil, Slovic \& Mertz 2007; Kahan, Hoffman \& Braman, in press). After being supplied with a brief definition of synthetic biology, ${ }^{2}$ subjects answered a set of questions aimed at determining their perception of the risks and benefits of synthetic biology. For comparison, they also rated the seriousness of four other environmental, technological, or health risks: those associated with global warming, nuclear power, genetically modified foods, and mad cow disease. ${ }^{3}$

The primary aim of the study was to initiate an investigation of the impact of cultural cognition on synthetic biology risks. Cultural cognition refers to the disposition of individuals to adopt beliefs about the risks and benefits of putatively dangerous activities that reflect their cultural appraisals of such activities. Persons who are relatively egalitarian and communitarian, for example, associate commerce and industry with unjust disparities in wealth and selfishness;

\footnotetext{
${ }^{1}$ More information on the sample and the sampling methods of Polimetrix can be found in Appendix B.

2 "Synthetic biology is a novel form of science that will allow scientists to design and build new biological organisms.”

3 Items from the survey appear in Appendix A.
} 
they thus find it congenial to believe that these activities are harmful to society and should be restricted. Persons who are relatively individualistic and hierarchical, in contrast, value commerce and industry as symbols of individual initiative and of the authority of societal elites; because recognition of environmental risks would justify restrictions on commerce and industry, such persons are generally skeptical of environmental risk claims (Douglas \& Wildavsky 1982). These dynamics have been shown to inform disagreement over various risks, including those associated with global warming (Leiserowitz 2005), nuclear power (Peters \& Slovic 1996), and nanotechnology (Kahan, Slovic, Braman, Gastil, \& Cohen, under review).

CCP is interested in determining whether and how this dynamic influences attitudes toward synthetic biology. A complete investigation of this topic would require more focused experimental investigations, which could be used to identify the mechanisms through which cultural worldviews shape synthetic biology risk perceptions and risk-communication strategies that make the best available scientific findings accessible to persons of diverse outlooks. The informed design of such studies-indeed, the utility of even attempting to design themdepends, however, on knowing how individuals of varying cultural identities perceive synthetic biology risks. This study performs that function.

\section{Study Findings}

We present the study findings in three steps. We start with descriptive data that summarize (self-reported) familiarity with synthetic biology and opinion about it overall and across distinct groups. We then present a more fine-grained multivariate analysis that assesses the relative impact of particular individual characteristics on perceptions of synthetic biology risks and benefits. Finally, for purposes of comparison, we present data on how study respondents reacted to various other types of risks.

\section{Survey Data}

Descriptive data are presented in Figure 1 and Figure 2 and in Table 1. That data suggest modest support over all, but also incipient public dissensus of a fairly distinctive kind. 
How much would you say you knew about synthetic biology before today?

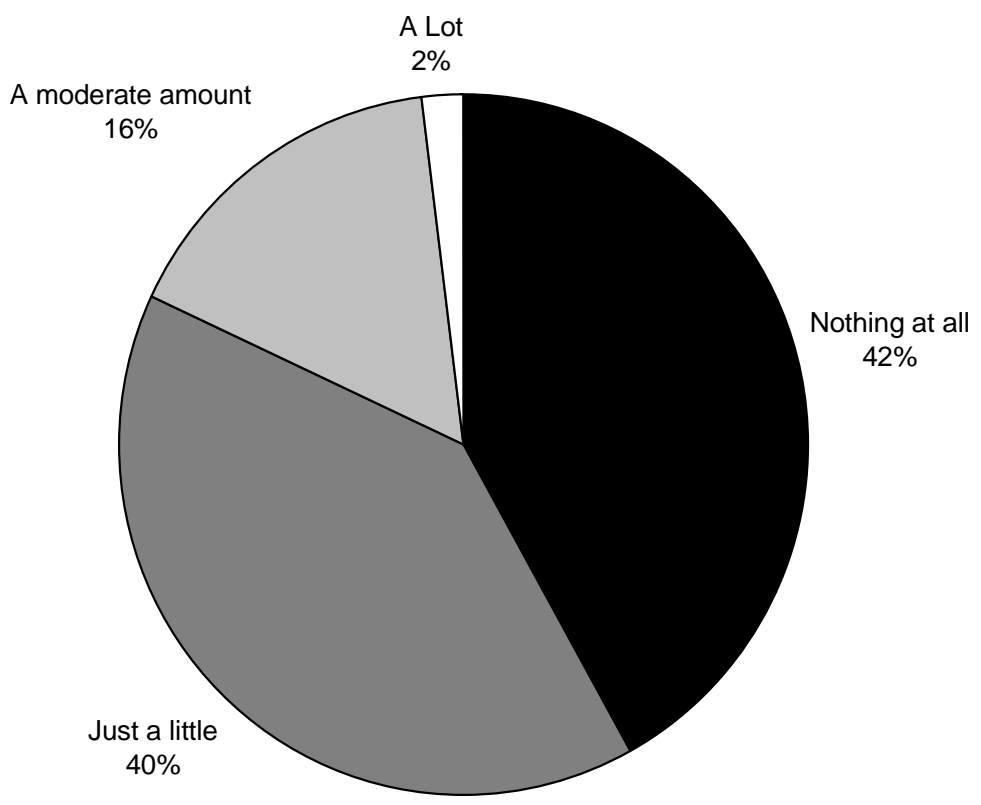

Figure 1. Overall Familiarity with Synthetic Biology

Most Americans, the survey suggests, are not very familiar with synthetic biology (Figure 1). Some $82 \%$ of the respondents reporting knowing either "nothing at all” or "just a little" about it before the study. Sixteen percent reported knowing a "moderate amount," while only 2\% reported knowing “a lot. 
On the whole, the benefits of synthetic biology will outweigh the risks

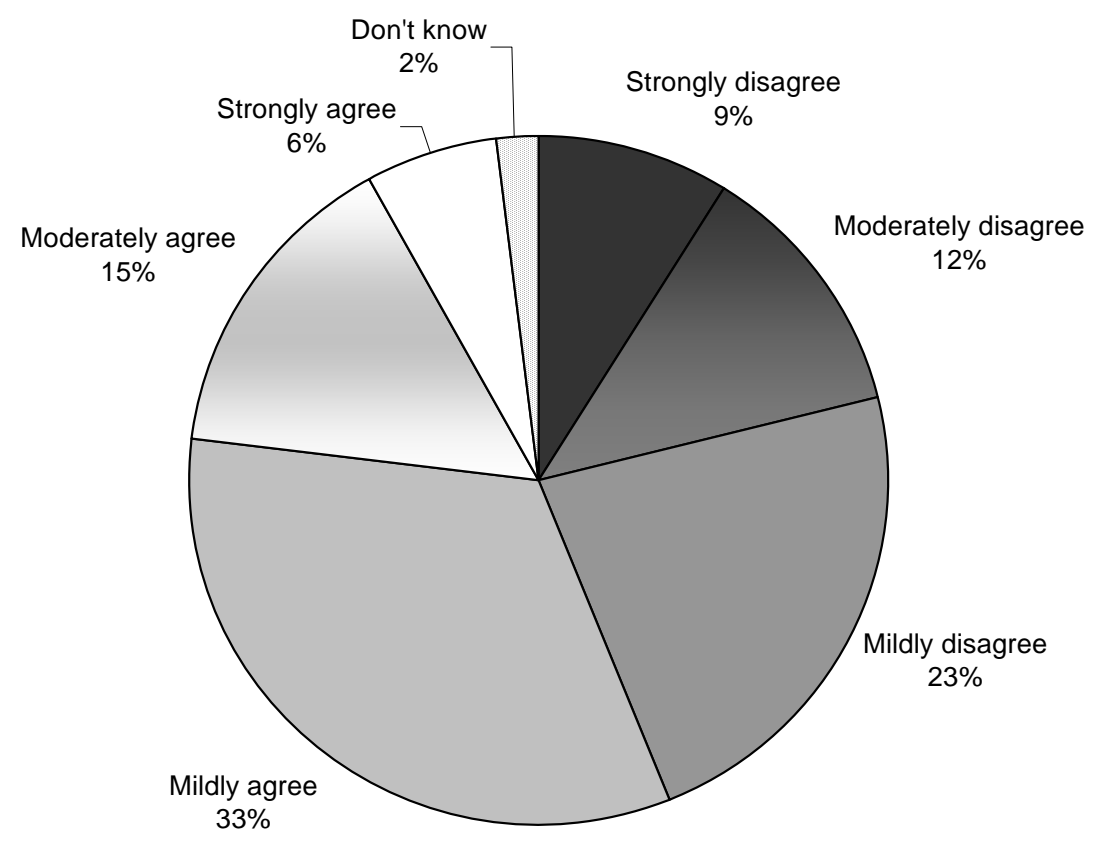

Figure 2. Overall Opinion on Balance of Benefits and Risks

Despite this degree of unfamiliarity, most subjects—-98\%—ventured an opinion one way or the other on the risks and benefits of synthetic biology. A majority-54\% to $43 \%$, well within the survey's $2.5 \%$ margin of error-agreed that the "benefits of synthetic biology will outweigh its risks” (Table 1). However, a majority (56\%, Figure 2) also either agreed only mildly with this proposition or mildly disagreed with it. Clearly, then, the public is somewhat ambivalent.

How familiar respondents reported being with synthetic biology did not show a strong association with their perceptions of its risks and benefits. Fifty-six percent of the respondents who were "relatively familiar" synthetic biology (that is, those who professed to know a "moderate amount" or "a lot") agreed that its benefits would outweigh its risks, and 54\% of those who were "relatively unfamiliar" (those who reported knowing either "a little" or "nothing at all" about it) did too (Table 1), a difference within the survey margin of error. 


\begin{tabular}{lrcc} 
& & \multicolumn{2}{c}{ Benefits $>$ Risks } \\
Overall & $n$ & Agree & Disagree \\
\cline { 2 - 4 } Men & 1,500 & $54 \%$ & $43 \%$ \\
Women & 717 & $\mathbf{6 0 \%}$ & $\mathbf{3 9 \%}$ \\
\hline Whites & 783 & $\mathbf{5 0 \%}$ & $\mathbf{5 0 \%}$ \\
Minorities & 1040 & $\underline{56 \%}$ & $\underline{43 \%}$ \\
\hline Relatively Familiar & 426 & $\underline{51 \%}$ & $\underline{48 \%}$ \\
Relatively Unfamiliar & 267 & $56 \%$ & $44 \%$ \\
\hline College Degree (or better) & 1233 & $54 \%$ & $44 \%$ \\
No College Degree & 409 & $57 \%$ & $43 \%$ \\
\hline Republicans & 966 & $55 \%$ & $\mathbf{4 5 \%}$ \\
Democrats & 432 & $\mathbf{4 8 \%}$ & $\mathbf{5 1 \%}$ \\
\hline Liberals & 479 & $\mathbf{5 9 \%}$ & $\mathbf{3 9 \%}$ \\
Conservatives & 304 & $\mathbf{6 4 \%}$ & $\mathbf{3 4 \%}$ \\
\hline High Concern-Other Risks & 495 & $\mathbf{4 7 \%}$ & $\mathbf{5 2 \%}$ \\
Low Concern-Other Risks & 781 & $\mathbf{4 8 \%}$ & $\mathbf{5 2 \%}$ \\
\hline Regular Church Goer & 719 & $\mathbf{6 2 \%}$ & $\mathbf{3 6 \%}$ \\
Not Regular Church Goer & 558 & $\mathbf{5 3 \%}$ & $\mathbf{4 6 \%}$ \\
\hline Hierarchs & 888 & $\mathbf{6 0 \%}$ & $\mathbf{3 9 \%}$ \\
Egalitarians & 759 & $\mathbf{5 1 \%}$ & $\mathbf{4 8 \%}$ \\
\hline Individualists & 741 & $\mathbf{5 8 \%}$ & $\mathbf{4 1 \%}$ \\
Communitarians & 763 & $54 \%$ & $46 \%$ \\
\hline Pcts. refer to percentage who “agreed” or “disagreed” at some level with \\
SYNBIOBALANCE. Bold denotes significance difference in \%”s of paired \\
groups at $p<.05$, underscore at $p<.10$, in difference between means of paired \\
groups of subjects. Overall margin of error $\pm 2.5 \%$ at $95 \%$ level of confidence. \\
\hline
\end{tabular}

\section{Table 1. Perceptions of Balance of Synthetic Biology Risks and Benefits}

This finding was modestly surprising. Persons who are familiar with a novel and relatively obscure technology are usually being impelled to learn more by some influence that is also likely to predispose them to form a particular view, either positive or negative, about its risks. In the case of nanotechnology, for example, a high degree of familiarity is strongly associated with the perception that benefits outweigh risks; the reason is that persons who have a strong cultural predisposition to value technology are motivated by that same predisposition both to find out about nanotechnology and to like what they learn about it (Kahan, Braman, Gastil, Slovic \& Cohen 2008). But something different seems to be going on with synthetic biology. Because the close division (56\% to $44 \%$ ) among those who are familiar with it mirrors the division among those who are relatively unfamiliar, one might infer that the knowledge vanguard includes both groups predisposed to see risk and groups predisposed to see benefits in this novel technology.

Both sorts of groups, our data suggest, exist in the population. Women, for example, are significantly more likely than men to see risks as predominating over benefits. Minorities, too, are more likely to see risk predominating over benefits than whites. These patterns are consistent with those observed for environmental and technological risks generally, where researchers have described them as the "white male effect” (Finucane, Slovic, Mertz, Flynn \& Satterfield 2000). 
Persons who are less concerned than average about other sources of risk-nuclear power, global warming, genetically modified foods, and mad cow disease-are also significantly less likely to see synthetic biology as more risky than beneficial than are persons who are more concerned than average with those risks.

But the parallel between synthetic biology risk perceptions and other risks ends there. Studies typically find that liberals and Democrats are more concerned with environmental and technological risks than are conservatives and Republicans (Leiserowitz 2005). With synthetic biology, these positions are reversed. Similarly, a high degree of religiosity predicts skepticism toward environmental risks (ibid.); but with synthetic biology, regularity of church attendance is strongly associated with higher risk concern.

Being politically conservative and highly religious tends to cohere with a "hierarchical" cultural worldview, one that stresses the importance of authority and embraces highly differentiated social roles. But whereas persons holding hierarchical values, too, tend to be highly skeptical of environmental risks generally, in the case of synthetic biology, they are more concerned than are persons holding more egalitarian values. Persons who hold individualistic cultural values, who also tend to be risk skeptical, have views of synthetic biology that are no different from those of persons holding more communitarian values. However, professing no religious attachments, a state that correlates with a lower degree of social attachment (Putnam 2000), does predict less concern with synthetic biology risks relative to its benefits.

\section{Multivariate Analysis}

Multivariate analysis sharpens the image of the distinctive cultural profile of synthetic biology risk perceptions. This analysis reflects the independent contribution that each subject characteristic makes to synthetic biology risk-benefit perceptions. As reflected in Table $2,{ }^{4}$ being male predicts a greater likelihood of perceiving benefits as predominating over risks even after other influences are taken into account, but so does being liberal. A greater perception of other risks (as measured in a scale that aggregates concerns with the four other types of risks that respondents rated $)^{5}$ predicts a greater likelihood of judging risks to predominate over benefitsbut so do being hierarchical and more regularly attending church. Controlling for these influences, neither being white nor being a Democrat significantly predicts a grater or lesser likelihood of seeing benefits as predominating over risks. Increased familiarity does now predict a greater likelihood of seeing benefits as greater, but only at a marginally significant level ( $p=$ .07). Greater education, surprisingly, predicts a smaller likelihood of perceiving benefits as greater than risks once the effect of other influences have been taken into account.

${ }^{4}$ For purposes of multivariate analysis, the 6-point SYNBIOALANCE item was truncated into a dichotomous variable that reflected agreement or disagreement with the statement that "[o] $n$ the whole, the benefits of synthetic biology will outweigh the risks."

5 Those risks formed a reliable scale $(\alpha=.70)$. 


\begin{tabular}{|c|c|}
\hline Predictor & $B$ \\
\hline Male & $\begin{array}{c}\mathbf{0 . 2 9} \\
(0.12)\end{array}$ \\
\hline White & $\begin{array}{c}0.19 \\
(0.13)\end{array}$ \\
\hline Age & $\begin{array}{c}0.00 \\
(0.00)\end{array}$ \\
\hline Income & $\begin{array}{c}0.02 \\
(0.02)\end{array}$ \\
\hline Education & $\begin{array}{c}-\mathbf{0 . 0 9} \\
(0.04)\end{array}$ \\
\hline Democrat (vs. Nondemocrat) & $\begin{array}{c}0.12 \\
(0.14)\end{array}$ \\
\hline Conservative (vs. Liberal) & $\begin{array}{c}-0.22 \\
(0.07)\end{array}$ \\
\hline No Religious Affiliation & $\begin{array}{c}0.16 \\
(0.13)\end{array}$ \\
\hline Regularity of Church Attendance & $\begin{array}{c}-\mathbf{0 . 1 4} \\
(0.05)\end{array}$ \\
\hline Concern with Other Environmental Risks & $\begin{array}{c}-\mathbf{0 . 7 1} \\
(0.09)\end{array}$ \\
\hline Familiarity with Synbio & $\frac{0.13}{(0.07)}$ \\
\hline Hierarchy (vs. Egalitarianism) & $\begin{array}{c}-0.26 \\
(0.08)\end{array}$ \\
\hline Individualism (vs. Communitarianism) & $\begin{array}{c}-0.13 \\
(0.09)\end{array}$ \\
\hline McKelvey \& Zavoina’s $R^{2}$ & 0.12 \\
\hline
\end{tabular}

\section{Table 2. Ordered Logistic Regression Analysis of Perception of Synthetic Biology Risks and Benefits}

The relative significance of these influences is illustrated in Figure 3. Derived from the regression model in Table 2, this Figure shows the extent to which variation in any of the statistically significant predictor influences the likelihood that a person will see synthetic biology benefits as predominating over its risks controlling for the influence of the remaining predictors. All else equal, a person who is one standard deviation more egalitarian than the mean is $7 \%$ more likely to see benefits as predominating over risks, while a person who is one standard deviation more hierarchical is $7 \%$ less likely to form that perception. Highly religious individuals - ones who attend church at least once a month are 6\% less likely to see benefits as predominating over risks than is the average person in the population; someone who rarely attends church is $4 \%$ more likely to see benefits as predominating over risks. The influence of being one standard deviation more liberal or one standard deviation more conservative has comparable effects, while gender and differences in education level have smaller ones. A one standard deviation change in 
concern with other risks generally has the largest impact when all other influences are controlled for.

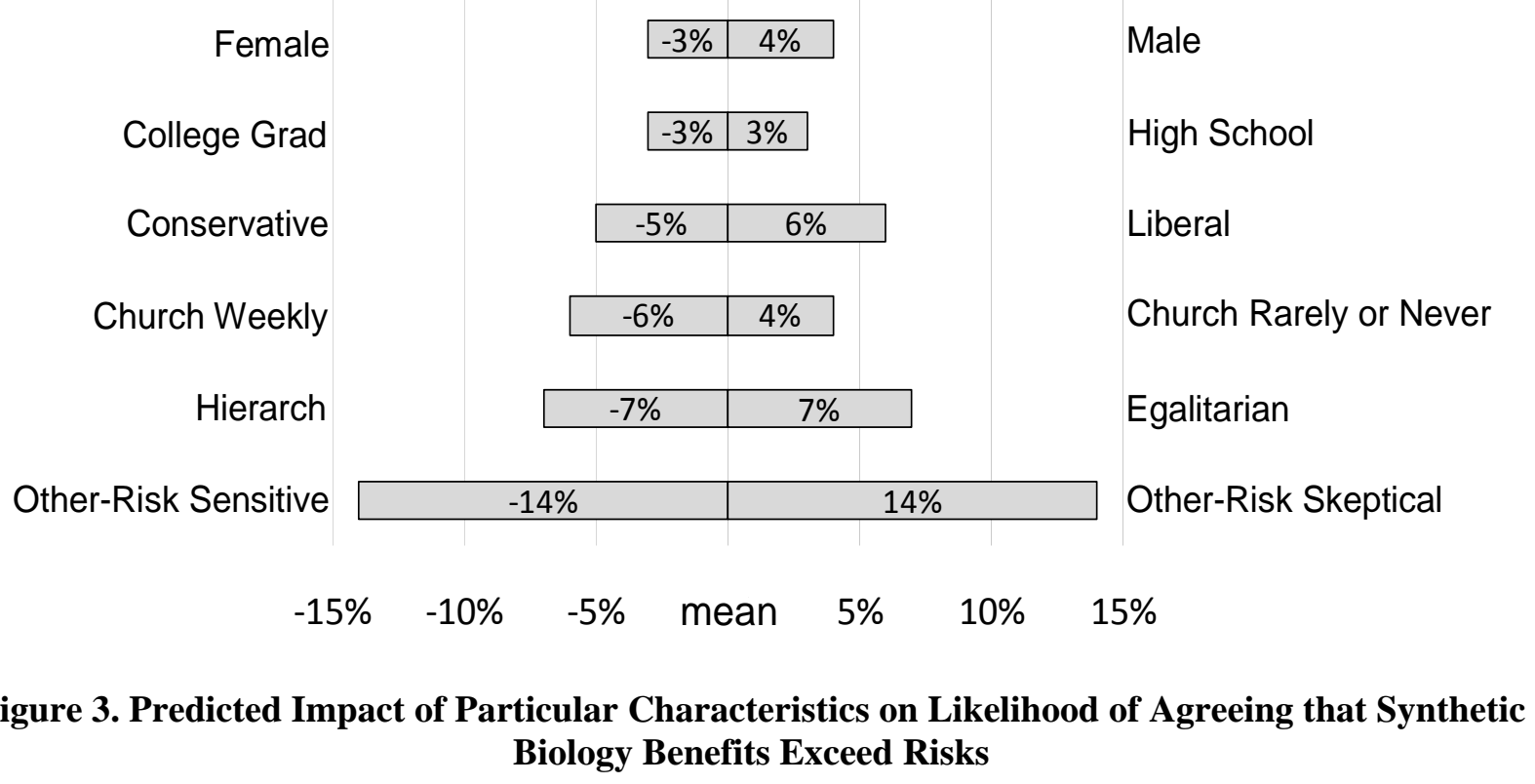

\section{Other Risks}

Survey respondents perceptions of the other risks display patterns consistent with those observed in studies of the cultural cognition of risk perception generally. Accordingly, the discrepancy between respondents' perceptions of these risks and their perceptions of synthetic biology risks corroborates the unusual character of the cultural profile of the latter.

Table 3 compares perceptions of environmental and health risks generally (measured, as above, by a scale combining responses to the other risks) ${ }^{6}$ and synthetic biology risk perceptions (as measured in a scale that combines responses to separate measures of risks, benefits, and the balance of risks and benefits). Whereas hierarchy predicts more concern for synthetic biology risks, it predicts less concern for other risks, as does individualism. Whereas ideological conservatism predicts more concern with synthetic biology risks, it predicts less for other risks. Religiosity predicts greater concern for synthetic biology risks, but not for other risks. Both synthetic biology risk perceptions and other risk perceptions display a white male effect.

\footnotetext{
6 The items appear in Appendix A. The Cronbach’s alpha for this scale was .59.
} 


\begin{tabular}{|c|c|c|}
\hline Predictor & Synbio Risks & Other Risks \\
\hline Male & $\begin{array}{c}\mathbf{- 0 . 2 8} \\
(0.05)\end{array}$ & $\begin{array}{c}\mathbf{- 0 . 3 1} \\
(0.03)\end{array}$ \\
\hline White & $\begin{array}{l}-\mathbf{- 0 . 2 2} \\
(0.05)\end{array}$ & $\begin{array}{l}-\mathbf{- 0 . 1 6} \\
(0.04)\end{array}$ \\
\hline Age & $\begin{array}{c}0.00 \\
(0.00)\end{array}$ & $\begin{array}{c}0.00 \\
(0.00)\end{array}$ \\
\hline Income & $\begin{array}{c}\mathbf{- 0 . 0 2} \\
(0.01)\end{array}$ & $\begin{array}{c}\mathbf{- 0 . 0 3} \\
(0.01)\end{array}$ \\
\hline Education & $\begin{array}{l}-0.01 \\
(0.02)\end{array}$ & $\begin{array}{c}\mathbf{- 0 . 0 6} \\
(0.01)\end{array}$ \\
\hline Democrat (vs. Nondemocrat) & $\begin{array}{c}0.01 \\
0.06)\end{array}$ & $\begin{array}{c}\mathbf{0 . 0 8} \\
(0.04)\end{array}$ \\
\hline Conservative (vs. Liberal) & $\begin{array}{c}\mathbf{0 . 1 0} \\
(0.03)\end{array}$ & $\begin{array}{l}-\mathbf{0 . 0 6} \\
(0.02)\end{array}$ \\
\hline No Religious Affiliation & $\begin{array}{c}-\mathbf{0 . 1 3} \\
(0.07)\end{array}$ & $\begin{array}{l}-\mathbf{0 . 1 5} \\
(0.05)\end{array}$ \\
\hline Regularity of Church Attendance & $\begin{array}{c}\mathbf{0 . 0 9} \\
(0.02)\end{array}$ & $\begin{array}{l}-0.01 \\
(0.01)\end{array}$ \\
\hline Hierarchy (vs. Egalitarianism) & $\begin{array}{c}\mathbf{0 . 0 9} \\
(0.03)\end{array}$ & $\begin{array}{c}-\mathbf{0 . 1 9} \\
(0.02)\end{array}$ \\
\hline Individualism (vs. Common.) & $\begin{array}{l}-0.01 \\
(0.04)\end{array}$ & $\begin{array}{c}-\mathbf{0 . 1 3} \\
(0.02)\end{array}$ \\
\hline Constant & $\begin{array}{c}1.82 \\
(0.17)\end{array}$ & $\begin{array}{c}\mathbf{4 . 6 6} \\
(0.12)\end{array}$ \\
\hline$R^{2}$ & 0.11 & 0.33 \\
\hline
\end{tabular}

\section{Table 3. Linear Regression Analyses of Synthetic Biology and Other Risk Perceptions}

Table 4 examines the perceptions of other risks individually. As expected, hierarchical and individualistic values both predict risk skepticism relative to egalitarian and communitarian ones for global warming, nuclear power, and mad cow disease. Also as expected, regularity of church attendance likewise predicts skepticism about global warming, although controlling for other influences, it exerts no influence on other risk perceptions. Conservativism predicts greater risk skepticism, and liberalism greater risk sensitivity, for global warming. All of these relationships are at odds with those observed for synthetic biology risk perceptions. Being white and male predicts less risk sensitivity for all other risks except global warming, which (consistent with Kahan, Braman, Gastil, \& Mertz 2007) displays only a gender and not a race effect after hierarchy and individualism are controlled for. 


\begin{tabular}{|c|c|c|c|c|}
\hline \multirow[b]{2}{*}{ Predictor } & \multicolumn{4}{|c|}{ Dependent Variable Risk Measures } \\
\hline & $\begin{array}{c}\text { Global } \\
\text { Warming }\end{array}$ & $\begin{array}{c}\text { Nuclear } \\
\text { Power }\end{array}$ & $\begin{array}{l}\text { Mad Cow } \\
\text { Disease }\end{array}$ & $\begin{array}{c}\text { Genetically } \\
\text { Modified Food }\end{array}$ \\
\hline Male & $\begin{array}{l}\mathbf{- 0 . 2 5} \\
(0.11)\end{array}$ & $\begin{array}{c}\mathbf{- 0 . 9 6} \\
(0.10)\end{array}$ & $\begin{array}{c}\mathbf{- 0 . 4 6} \\
(0.10)\end{array}$ & $\begin{array}{c}\mathbf{- 0 . 7 2} \\
(0.00)\end{array}$ \\
\hline White & $\begin{array}{l}-0.07 \\
(0.12)\end{array}$ & $\begin{array}{l}-\mathbf{0 . 3 1} \\
(0.11)\end{array}$ & $\begin{array}{l}-\mathbf{0 . 5 4} \\
(0.11)\end{array}$ & $\begin{array}{l}-\mathbf{0 . 3 0} \\
(0.01)\end{array}$ \\
\hline Age & $\begin{array}{c}\mathbf{0 . 0 1} \\
(0.00)\end{array}$ & $\begin{array}{c}0.00 \\
(0.00)\end{array}$ & $\begin{array}{c}\mathbf{0 . 0 1} \\
(0.00)\end{array}$ & $\begin{array}{c}0.00 \\
(0.59)\end{array}$ \\
\hline Income & $\begin{array}{l}-0.04 \\
(0.02)\end{array}$ & $\begin{array}{l}\mathbf{- 0 . 0 8} \\
(0.02)\end{array}$ & $\begin{array}{l}\mathbf{- 0 . 0 6} \\
(0.02)\end{array}$ & $\begin{array}{l}-0.02 \\
(0.18)\end{array}$ \\
\hline Education & $\begin{array}{l}-0.02 \\
(0.04)\end{array}$ & $\begin{array}{l}\mathbf{- 0 . 1 9} \\
(0.04)\end{array}$ & $\begin{array}{l}\mathbf{- 0 . 1 7} \\
(0.04)\end{array}$ & $\begin{array}{l}\mathbf{- 0 . 1 4} \\
(0.00)\end{array}$ \\
\hline Democrat (vs. Nondemocrat) & $\begin{array}{c}\mathbf{0 . 3 6} \\
(0.13)\end{array}$ & $\begin{array}{c}0.07 \\
(0.12)\end{array}$ & $\begin{array}{c}0.14 \\
(0.12)\end{array}$ & $\begin{array}{c}0.03 \\
(0.78)\end{array}$ \\
\hline Conservative (vs. Liberal) & $\begin{array}{l}\mathbf{- 0 . 3 7} \\
(0.07)\end{array}$ & $\begin{array}{l}-0.09 \\
(0.07)\end{array}$ & $\begin{array}{c}0.00 \\
(0.06)\end{array}$ & $\begin{array}{l}-0.05 \\
(0.42)\end{array}$ \\
\hline No Religious Affiliation & $\begin{array}{l}-0.18 \\
(0.15)\end{array}$ & $\begin{array}{l}-\mathbf{- 0 . 3 0} \\
(0.14)\end{array}$ & $\frac{-0.25}{(0.14)}$ & $\begin{array}{l}\mathbf{- 0 . 4 3} \\
(0.00)\end{array}$ \\
\hline Regularity of Church Attendance & $\begin{array}{l}\mathbf{- 0 . 1 4} \\
(0.05)\end{array}$ & $\begin{array}{c}0.06 \\
(0.04)\end{array}$ & $\begin{array}{c}0.02 \\
(0.04)\end{array}$ & $\begin{array}{c}0.01 \\
(0.78)\end{array}$ \\
\hline Hierarchy (vs. Egalitarianism) & $\begin{array}{l}-0.91 \\
(0.08)\end{array}$ & $\begin{array}{l}-\mathbf{0 . 4 5} \\
(0.07)\end{array}$ & $\begin{array}{l}\mathbf{- 0 . 2 2} \\
(0.07)\end{array}$ & $\begin{array}{l}-0.09 \\
(0.19)\end{array}$ \\
\hline Individualism (vs. Commun.) & $\begin{array}{l}-0.53 \\
(0.08) \\
\end{array}$ & $\begin{array}{l}\mathbf{- 0 . 2 8} \\
(0.07)\end{array}$ & $\begin{array}{l}\mathbf{- 0 . 1 9} \\
(0.07) \\
\end{array}$ & $\begin{array}{l}-0.09 \\
(0.22) \\
\end{array}$ \\
\hline McKelvey \& Zavoina’s $R^{2}$ & 0.46 & 0.26 & 0.13 & 0.09 \\
\hline
\end{tabular}

Table 4. Ordered Logistic Regression Analysis of Other Risk Perceptions

The only other risk perception that does closely adhere to the usual pattern is the one of genetically modified foods. Although it shows a white male effect, the perception of genetically modified food risks is not significantly correlated with cultural worldviews, with political ideology, or with party affiliation. The absence of any religious affiliation predicts less concern with this risk, but religiosity (as reflected in regularity of church attendance) does not.

\section{Interpretation and Conclusions}

Intended to initiate more intensive experimental investigation, this study nonetheless supports a number of important conclusions. The first is that the potential risks of synthetic biology do in fact seem susceptible to generating significant public conflict. How to balance synthetic biology risks and benefits generates systematic divisions in public opinion despite the public's relative unfamiliarity with this novel science. This finding implies that individuals' reactions are driven by intuitive, likely highly affective (Slovic 2005), predispositions. Such predispositions, it has been shown, can subsequently influence how individuals evaluate information, thereby reinforcing individuals’ first impressions (Kahan, Slovic, Braman, Gastil \& Cohen 2008). Divisions among persons with opposing predispositions are thereafter likely to 
grow as individuals interact with and seek out information from others who share their values and who as a result are likely to share their predispositions (Kahan, Braman, Slovic, Cohen, Kysar \& Gastil 2008). If this occurs, synthetic biology could vulnerable to the sort of intense cultural conflict that has historically surrounded nuclear power and today surrounds global warming.

Second, and even more intriguingly, the nature of cultural conflict over synthetic biology is likely to have a distinctive character. Disputes over environmental and technological risks in American society typically involve disagreement between two cultural styles: one, featuring a hierarchical and individualistic worldview, that is risk skeptical; and another, featuring an egalitarian and communitarian worldview, that is risk sensitive. The incipient cultural division over synthetic biology, in contrast, is nearly the opposite. Hierarchical, conservative, and highly religious persons are the ones who fear synthetic biology the most. The ones who see the most benefit are persons who are relatively egalitarian, liberal, and secular.

What explains this unusual alignment? A likely possibility relates to the distinctive social meaning of synthetic biology risks. Individuals tend to impute risk to activities that symbolically threaten their values; they resist believing that society might be harmed by activities that affirm their values (Douglas 1966). Historically, concerns about acid rain, nuclear power production, global warming, and the like have connoted challenges to societal and governmental elites. This is a resonance congenial to persons who hold egalitarian views, but noxious to persons who hold hierarchical ones (Douglas \&Wildavsky 1986). Synthetic biology, however, seems to be attended by a different constellation of meanings that are themselves symbolically threatening to hierarchs. Like evolution, which conveys an uncompromisingly secular understanding of the origin of life, synthetic biology, because it presupposes human license over the career of it, seems to denigrate a set of cultural understandings that subordinate man to the authority of God. The denigration of those understandings is in turn subversive to the authority of certain institutions and norms traditionally integral to a hierarchical social ordering. Hierarchs, consistent with the logic of cultural cognition, thus impute danger to synthetic biology.

This is, of course, a conjecture. Or better, it is a hypothesis that, we believe, should be tested in appropriate experimental study.

Indeed, the third and most important conclusion of this study is the need for additional investigation of the cultural cognition of synthetic biology risks. The current study certainly furnishes no definitive conclusions about how cultural values are likely to shape public perceptions of synthetic biology, or what risk communicators should do to assure the public's beliefs are informed by the best available science. But we believe the study does indisputably demonstrate that these are questions researchers should be trying to answer. 


\section{References}

Cultural Cognition Project (2007). The Second National Risk and Culture Study: Making Sense of - and Making Progress In-The American Culture War of Fact.

Douglas, M. (1966). Purity and Danger: An Analysis of Concepts of Pollution and Taboo.

Douglas, M., \& Wildavsky, A. B. (1982). Risk and Culture : An Essay on the Selection of Technical and Environmental Dangers. Berkeley: University of California Press.

Finucane, M., Slovic, P., Mertz, C. K., Flynn, J., \& Satterfield, T. A. (2000). Gender, Race, and Perceived Risk: The "White Male" Effect. Health, Risk, \& Soc'y, 3(2), 159-172.

Kahan, D. M., Braman, D., Gastil, J., Slovic, P., \& Mertz, C. K. (2007). Culture and IdentityProtective Cognition: Explaining the White-Male Effect in Risk Perception. Journal of Empirical Legal Studies, 4(3), 465-505.

Kahan, D. M., Braman, D., Slovic, P., Gastil, J., \& Cohen, G. L. (under review). The Future of Nanotechnology Risk Perceptions: An Experimental Investigation of Two Hypotheses.

Kahan, D. M., Hoffman, D. A., \& Braman, D. (in press). Whose Eyes are You Going to Believe? Scott v. Harris and the Perils of Cognitive Illiberalism. Harv. L. Rev., 122.

Kahan, D. M., Slovic, P., Braman, Cohen, G. L., \& Gastil, J., (2008). Who Fears the HPV Vaccine, Who Doesn't, and Why?, Cultural Cognition Working Paper.

Kahan, D. M., Slovic, P., Braman, Cohen, G. L., \& Kysar, D. A. D., Gastil, J., (2008). Biased Assimilation, Polarization, and Cultural Credibility: An Experimental Study of Nanotechnology Risk Perceptions, Cultural Cognition Working Paper.

Leiserowitz, A. A. (2005). American risk perceptions: Is climate change dangerous? Risk Analysis, 25(6), 1433-1442.

Peters, E., \& Slovic, P. (1996). The Role of Affect and Worldviews as Orienting Dispositions in the Perception and Acceptance of Nuclear Power. Journal of Applied Social Psychology, 26(16), 1427-1453.

Putnam, R. D. (2000). Bowling Alone: The Collapse and Revival of American Community. New York: Simon \& Schuster. 


\section{Appendix A. Survey Items}

\section{Synthetic Biology Items}

Now we would like to know what you think about synthetic biology. Synthetic biology is a novel form of science that will allow scientists to design and build new biological organisms.

SYNBIOKNOW. How much would you say you knew about synthetic biology before today? [(1) nothing at all (2) just a little (3) a moderate amount (4) a lot ]

There is talk about the potential risks and benefits of synthetic biology. Please indicate how much you disagree or agree with these statements: [Strongly Disagree, Moderately Disagree, Mildly Disagree, Mildly Agree, Moderately Agree, Strongly Agree]

SYNBIOBENEFIT. The benefits of synthetic biology are likely to be very large.

SYNBIORISK. The risks of synthetic biology are likely to be very large.

SYNBIOBALANCE. On the whole, the benefits of synthetic biology will outweigh the risks.

\section{Other Risk Items}

We'd now like to know what you think about some potential risks facing our society. How much risk do you believe each of the following poses to the safety or health of people in our society? [Almost No Risk, Slight Risk, Moderate Risk, High Risk, Extremely High Risk]

GLOBWARM. Global Warming

COW. Mad Cow Disease

NUKEPOW. Nuclear Power

GENFOOD. Genetically Modified Food 


\section{Appendix B. Sample Information}

\section{Polimetrix}

Polimetrix (http://www.polimetrix.com/) is a public opinion research firm that conducts on-line surveys and experiments on behalf of academic and governmental researchers and commercial customers (including political campaigns). It maintains a panel of over 1 million Americans that is uses to construct representative study samples through a population-matching algorithm. For more information, http://www.polimetrix.com/documents/YGPolimetrixSampleMatching.pdf.

2. Demographic composition of sample for this study

a. Total number of subjects: 1,500 .

b. Gender: $52 \%$ female, $48 \%$ male.

c. Race: $72 \%$ white, $11 \%$ African-American.

d. Average age: 48 years.

e. Median household income: $\$ 40,000$ to $\$ 49,000$.

f. Median education level: Some college.

3. Date of survey

Mar. 26 to Mar. 31, 2008. 